Trinity University

Digital Commons @ Trinity

Psychology Faculty Research

Psychology Department

1994

\title{
Emotionality in Free Recall: Language Specificity in Bilingual Memory
}

L. J. Anooshian

Paula T. Hertel

Trinity University, phertel@trinity.edu

Follow this and additional works at: https://digitalcommons.trinity.edu/psych_faculty

Part of the Psychology Commons

Publication Details

Cognition and Emotion

\section{Repository Citation}

Anooshian, L.J., \& Hertel, P.T. (1994). Emotionality in free recall: Language specificity in bilingual memory. Cognition and Emotion, 8(6), 503-514. doi: 10.1080/02699939408408956

This Article is brought to you for free and open access by the Psychology Department at Digital Commons @ Trinity. It has been accepted for inclusion in Psychology Faculty Research by an authorized administrator of Digital Commons@ Trinity. For more information, please contact jcostanz@trinity.edu. 
COGNITION AND EMOTION, 1994, 8 (6), 503-514

\title{
Emotionality in Free Recall: Language Specificity in Bilingual Memory
}

\author{
Linda J. Anooshian and Paula T. Hertel \\ Trinity University, Texas, USA
}

\begin{abstract}
Bilingual subjects (Spanish/English) who had acquired fluency in their second language after 8 years of age rated 18 emotional and 18 neutral words for ease of pronunciation, implied activity, or emotionality; half of each type was presented in Spanish and half in English. During a subsequent, unexpected test of free recall subjects recalled more emotional than neutral words, but only for words that had been presented in the native language. This finding applied across native-language groups and suggests that emotion provides a basis for language specificity in bilingual memory.
\end{abstract}

\section{INTRODUCTION}

Consider the following scenario:

Rosie grew up in a Spanish-speaking home and became fluent in English between 8 and 12 years of age. By age 25, she infrequently used Spanish either at home or at work, but she prayed in Spanish because praying in English never "felt right". Rosie believed that the difference, although difficult to articulate, was important.

Similar to Rosie's experience, anecdotal reports from bilinguals frequently reveal specific language preferences when they want to express anger, love, or religious sentiment. The literature on bilingualism corroborates their reports. Bond and Lai (1986), for example, found that bilinguals spent more time discussing embarrassing topics in their secondlearned than first-learned language, which suggests that code-switching can

\footnotetext{
Requests for reprints should be sent to Linda J. Anooshian, Department of Psychology. Boise State University, 1910 University Drive, Boise, Idaho, ID 83725, USA.

Thanks are extended to Rose DeLuna for her efforts in preparing the materials and recruiting and testing subjects for the research reported here.
}

(C) 1994 Lawrence Erlbaum Associates Limited 
serve a distancing function. Similarly, Javier and Marcos (1989) speculate that switching to the second-learned language may reflect the bilingual's attempt to avoid anxiety-provoking materials. Researchers have reported that greater anxiety is produced by the presentation of emotional materials (e.g. expression of primitive emotions, taboo words) in the native relative to the second-learned language (Gonzalez-Reigosa, 1976; Javier, 1989; with anecdotal evidence from Buxbaum, 1949; Greenson, 1950). In reporting a study of Spanish-English code switching, Gumperz and Hernandez (1971) provide a detailed account of a woman in therapy who regularly vacillated between personal involvement (expressed in native Spanish) and clinical detachment (expressed in English). These various observations are consistent with the general hypothesis of the present research, that the advantage of emotion in bilinguals' memory will depend on the language of presentation.

The significance of our research is perhaps most apparent in the context of representational issues. Research on bilingualism often focuses on the issue of whether different languages access common representations in memory or separate, language-specific representations. The most accepted view holds that common representations of experiences and meanings are accessed by different linguistic forms (Gerard \& Scarborough, 1989; McCormack, 1977; Potter, So, Von Eckardt, \& Feldman, 1984; Schwanenflugel \& Rey, 1986; Smith, 1991). Yet documentations of language specificity are numerous (e.g. Kolers, 1963, 1968; Kolders \& Roediger, 1984; Marsh \& Maki, 1976; Scarborough, Gerard, \& Cortese, 1984; Watkins \& Peynircioglu, 1983). Faced with conflicting results regarding the viability of separate- versus common-store models, several authors have argued that the inconsistencies can only be resolved by considering the specific demands of different retrieval tasks (e.g. Durgunoglu \& Roediger, 1987; Smith, 1991; Snodgrass, 1984). For example, Durgunoglu and Roediger (1987) obtained evidence for language specificity only when the retrieval task was data-driven (i.e. a test of "implicit" memory in which word fragments are to be completed with the first word that comes to mind). Performance on a test of word recall was considered conceptually driven (i.e. driven by a meaning-based search). In that task, memory was unaffected by variations in language of presentation, but enhanced by elaborative processing during initial exposure. For the present research, we hoped to provide evidence that linguistic specificity could indeed be obtained on a test of deliberate meaning-based recall. Specifically, we postulated that emotional words would be recalled more often than neutral words only when those words are presented in the bilingual's native language. Linguistic specificity should be found when a particular language is a discriminative and ecologically important aspect of prior experience. 
Consistent with this perspective, Glucksberg (1984) proposed that the issue of language specificity is best viewed as a functional issue. From a functional perspective, the meanings of words are determined by the contexts in which they are established and re-established. If one particular language prevails in the contexts for establishing meaning, that language becomes integral to the structure of meaning or to the processes of its use. Consistent with this view, free associations to concepts differ as a function of language of presentation (Ervin, 1964; Kolers, 1963; MontiBelkaoui \& Belkaoui, 1983).

From a functional view, furthermore, the age of second-language acquisition should be an important factor in finding evidence for emotionrelated specificity. At a very early age, infants explore their world through sensorimotor interactions that necessarily involve affective interchanges (Anooshian \& Siegel, 1985; Escalona, 1981; Neisser, 1963). Bloom and her colleagues (Bloom \& Beckwith, 1989; Bloom \& Capatides, 1987) documented the close relationship in infancy between the expression of affect and language development and postulated further integration of affect and language as children learn to express emotion in different contexts. More generally, prior experience establishes the ways in which new events of a similar type are processed. As Kolers and Brison (1984, p. 111) note, "a practiced art often leads to a preference for a means". In the case of bilinguals, the extent to which early affective experiences are associated with just one language may therefore determine the extent to which later experiences continue to be associated with their native language. Bilinguals should continue to use the native language in emotional situations if emotional experiences were associated with that language in early childhood, thereby becoming practised in expressing emotion in that native language. These assumptions led us to recruit bilinguals who learned their second language beyond early childhood.

In a preview of the design, bilingual subjects judged Spanish and English emotional and neutral words in three orienting tasks (requiring the rating of words on specific dimensions). Then they took an unanticipated test of free recall, which is often enhanced by the emotional value of verbal material (see Boggiano \& Hertel, 1983; Dutta, 1975; Rubin \& Friendly, 1986). Possible explanations for the advantage of emotional words rely on their differential elaboration or intra-list associations. First, a richer and more diverse set of instances and episodes may be recruited as elaborations for emotional concepts relative to neutral concepts. If so, according to our framework, the advantage should not extend to the bilinguals' second-learned language. Secondly, the recall advantage for emotional words might indicate that inter-item associations are more numerous among emotional words. But this is likely only if emotion is a salient characteristic of experience with these words. For the native- 
Spanish speaker, "mother" is no more likely to be associated with "church" than "table" is with "street". "Madre" and "iglesia", on the other hand, should be more highly associated than "mesa" and "calle". Hence, an advantage for emotional words should hold only in the native language (as it typically does in monolingual research).

The recall advantage for emotional words might further depend on the nature of the orienting task. Subjects rated both emotional and neutral words by considering one of three dimensions: emotional intensity, degree of activity inherent in the word, or ease of pronunciation. Judgements of activity and ease of pronunciation were chosen because they are unemotional tasks that differ in the extent to which they provide some elaborative or categorical basis for retrieval. Because activity is an aspect of meaning (see Osgood, 1952), recall should benefit from such ratings, in comparison to ratings for ease in pronunciation, which would not seem to provide a very useful basis for deliberate retrieval. In both processing conditions, moreover, finding a recall advantage for emotional words would suggest that the emotional dimension is processed spontaneously and subsequently relied on to guide retrieval.

Finally, we included two groups of English-Spanish bilinguals who differed in terms of whether English or Spanish was the native language. We considered this aspect of the design to be critical to establishing the generality of our findings. In recruiting all subjects from the same American city (with a large Hispanic population), one must assume significant group differences. The two groups might well have learned the second language for different purposes and in different contexts (see Grossjean, 1982). Beyond establishing generality, the inclusion of both native English and native Spanish speakers was essential to ensure clear interpretations of our findings. Clearly, a finding of emotional specificity in one group alone would invite a host of plausible alternative explanations or puzzling questions (e.g. the issue of greater emotionality for Spanish words relative to their English counterparts and questions about the local dialect or specific language experiences of our sample). Hence, our experiment was designed to demonstrate a recall advantage for emotional over neutral words presented in the bilinguals' native language independent of whether that native language was Spanish or English.

\section{METHOD}

\section{Subjects}

The 36 subjects selected for the study were fluent in both English and Spanish. Spanish was the native language for half the subjects and English was the native language for the other half. Fluency in the second language 
was not acquired prior to 8 years of age, according to self-reports. (The mean age of acquisition for the second language was 16.3 years for the native Spanish speakers and 18.4 years for the native English speakers.) The two groups were fairly comparable in terms of education level (Ms $=15.8$ and 17.8 years, respectively) and age $(M s=28$ and 32 years, respectively). Each subject was paid $\$ 7.00$ for participation.

The subjects were selected on the basis of information gathered in a telephone interview. We required that the native language was the one that was used most frequently at home during the subjects' childhood and was the language of instruction for at least most of their elementary education. Fluency in two languages was assessed via both the telephone interview and performance on a short test of fluency, developed by MacNamara (1967). All subjects rated and described themselves as fluent in both languages during the interview. (Self-evaluations have been found to be highly correlated with performance on profiency tests; Fishman and Cooper, 1969.) Nevertheless, prior to the experimental task, we administered word-naming and word-association tests in both English and Spanish (see MacNamara, 1967). When asked to say as many words as possible in a 1-minute period (word naming), the two groups did not differ on the English version ( $M s=32.9$ and 33.9 for Spanish and English speakers, respectively). However, for naming words in Spanish, the native Spanish speakers produced more words $(M=34.0)$ than did the native English speakers $(M=27.4), t(34)=2.44, P<0.05$. The two groups performed comparably in word association tasks in which subjects were given 1 minute to produce associations to each of three words in each of the two languages. In short, although the overall evidence confirmed that subjects were fluent in both languages, there was some indication that native English speakers were not as fluent in Spanish as were native Spanish speakers in English.

\section{Word Lists}

English words were selected such that the sets of 18 emotional and 18 neutral words were comparable in terms of concreteness (Brown \& Ure, 1969), frequency (Thorndike \& Lorge, 1944), frequency of the Spanish translation (Russell, 1947), and word length (number of letters; for both English and the Spanish versions; see the Appendix). According to Brown and Ure's (1969) norms for English words, the mean rating for emotionality (on a 7-point scale) was 5.69 for the 18 emotional words (range: $5.0-6.9$ ) and 1.99 for the 18 neutral words (range: 1.36-2.82). Because less normative information was available for Spanish words, we selected English words that could be translated into Spanish with minimal ambiguity, according to native Spanish speakers. Because no method for selecting 
words can be devoid of problems or potential criticism, we examined ratings in the orienting tasks for possible evidence of differences according to language of presentation.

Two lists of the 36 words were constructed. The first half of each list contained the same randomly selected emotional and neutral words ( 9 each), but they were presented in English on the first list and Spanish on the second. The second half of each list was similarly constructed, but contained Spanish words on the first list and English words on the second. Assignment of words to halves was random with the exception that high associates (i.e. "table" and "chair") were placed in different halves. Within each, the words were further divided into 3 blocks containing 3 emotional and 3 neutral words. These words were randomly arranged within blocks and each block was assigned to one of the three rating tasks. Across subjects, each block of words occurred equally often in each position of the list and was rated equally often in each task.

\section{Procedure}

Following the fluency tests, subjects completed the orienting task that required rating each of the 36 words for its ease of pronunciation, implied activity, or emotionality. Half of the subjects in each native-language category were assigned to each word list. Hence, each subject rated 18 words in one language followed by 18 words in the other language; half the subjects rated words in their native language first and the other half rated words in the second-learned language first.

Instructions and descriptions of the rating scales were provided in both written and oral form in the same language as the words in the first half of the list, and repeated in the other language before the second. For each block of 6 words assigned to a particular rating task, the subject used a separate sheet of paper containing 6 Likert scales (7-point) with endpoints labelled in accordance with the type of rating. For rating ease of pronunciation, subjects were told to rate "how easily, or with how much difficulty" they could pronounce the word aloud [from "easy to say" (1) to "hard to say" (7)]. For activity ratings, subjects were told to decide "how much activity was inherent" in the meaning of a particular word [from "active" (1) to "inactive" (7)]. Finally, for emotionality ratings, subjects were told to consider the intensity (rather than type) of emotion associated with the meaning of the word [from "unemotional" (1) to "emotional" (7)].

Following these instructions, each word was presented on a monochrome monitor for $5 \mathrm{sec}$, followed by a $6 \mathrm{sec}$ inter-word interval. The subjects therefore had a total of $11 \mathrm{sec}$ to read and rate each word. A $10 \mathrm{sec}$ interval between blocks allowed sufficient time to turn to the next rating scale. 
The rating task was followed by an unexpected test of free recall. Subjects were told that accurate spelling was not important, but to attempt to write as many of the 36 words as they could remember from the rating tasks. Subjects who initially wrote fewer than 20 words were prompted to continue until at least 20 words had been produced.

\section{RESULTS}

\section{Recall}

The proportions of words correctly recalled were submitted to an analysis of variance that employed the multivariate approach to within-subjects factors. When the assumption of homoscedasticity was violated, we report approximate univariate $F$ s that conform to Wilks Lambda. Preliminary analyses indicated no significant effects associated with word lists, block orders, or task orders. Hence, the single between-subjects factor for further analyses was bilingual group (native Spanish or native English). The three within-subject factors included the emotionality of the rated word (emotional vs. neutral), language of presentation (native vs. second language), and rating task (pronunciation, activity, or emotionality). The significance level for all analyses was set at 0.05 . When factors entered into reliable interactions, their lower-order effects are not reported.

First, it is important to note that the analysis revealed no reliable effects involving the between-subjects factor of bilingual groups. Therefore, in our subsequent descriptions of effects involving language of presentation, the term "native language" refers to Spanish words for half of the subjects and English words for the other half. "Second language" should be interpreted similarly. Further, in considering interactions involving language of presentation, we report follow-up analyses within each language of presentation (native or second). This approach was taken because it is difficult to interpret native versus second language differences. Neither past literature nor this experiment can provide a reasonable basis for clearly predicting or interpreting effects for language of presentation (e.g. differential recall of neutral words presented in the native relative to the second language). This approach, moreover, was dictated by our predictions (e.g. emotionality effects specific to native-language presentation).

As can be seen from the means in Table 1, our predictions regarding the effects of emotionality were confirmed. The analysis of recall proportions revealed the expected interaction of emotionality with language of presentation, $F(1,34)=10.50, M S_{\mathrm{e}}=0.53$. More emotional than neutral words were recalled when the words were presented in the native language, $F(1,34)=11.03, M S_{\mathrm{e}}=3.26$, but not when presented in the second language. The experiment was also designed to discover if this 
TABLE 1

Mean Proportions of Words Recalled for Different Rating Tasks and Types of Words

\begin{tabular}{lcccc}
\hline & \multicolumn{3}{c}{ Rating Task } & \\
\cline { 2 - 3 } Type of Word & Pronounce & Activity & Emotion & Overall \\
\hline Native language & & & & \\
Emotional & 0.37 & 0.54 & 0.58 & 0.50 \\
Neutral & 0.24 & 0.53 & 0.39 & 0.38 \\
Overall & 0.31 & 0.54 & 0.49 & 0.44 \\
Second language & & & & \\
Emotional & 0.40 & 0.47 & 0.48 & 0.45 \\
Neutral & 0.52 & 0.49 & 0.46 & 0.49 \\
Overall & 0.46 & 0.48 & 0.47 & 0.47 \\
\hline
\end{tabular}

predicted interaction further depended on the type of rating task. Although the effect of emotionality for words presented in the subjects' native language appeared to vary across rating tasks, the three-way interaction (emotionality $\times$ language of presentation $\times$ rating task) was not reliable.

The only other reliable effect was the two-way interaction between rating task and language of presentation, $F(2,33)=8.14$, Wilks Lambda $=0.669$. Regardless of emotionality, rating the ease of pronunciation led to lower recall than did rating activity or emotionality only when the words were presented in the native language, $F(1,34)=20.85, M S_{c}=10.32$.

Finally, it should be noted that subjects rarely recalled the right concept in the wrong language (e.g. recalled a Spanish translation of a word that had been presented in English). The mean proportion of such errors ranged from 0.00 to 0.06 across conditions. The analyses reported here were performed on the proportion of words that were recalled in the presented language. However, analyses of recall in either language revealed the same pattern of effects.

\section{Ratings}

As noted earlier, the emotional ratings provided by subjects in the orienting task allowed us to evaluate the appropriateness of our word choices. Emotional and neutral words were selected on the basis of normative information about the perceived emotionality of the English words, but similar information was not available for perceived emotionality of their Spanish counterparts. We submitted emotional ratings to an analysis of variance, with factors for bilingual group, language of presentation, and emotionality (our categories of emotional and neutral words). The absence of any effects involving language (bilingual group or language of presentation) confirmed that our English and Spanish word lists were relatively comparable for native speakers of both languages. The only 
reliable effect was a main effect of emotionality, $F(1,34)=362.13, M S_{e}$ $=1.36$. Mean ratings were 5.79 for emotional words and 2.09 for neutral words.

The same analysis for activity ratings similarly revealed the sole reliable effect of emotionality, $F(1,34)=173.99, M S \mathrm{e} 2=1.15$. Emotional words were judged to be more active than neutral words $[M \mathrm{~s}=2.65$ and 5.01, respectively [ $(1=$ "active"; $7=$ "inactive")]. Finally, the analysis of ratings for ease of pronunciation revealed a main effect of language of presentation. Unexpectedly, words presented in the second language were rated as easier to pronounce $(M=1.40)$ than words presented in the native language $(M=1.91 ; 1=$ "easy to say"; $7=$ "hard to say"). Further reliable interactions with emotional value and bilingual group were also obtained, but probable floor effects confound their interpretation.

\section{DISCUSSION}

As expected, emotional words were recalled more frequently than neutral words, but only following presentation in the native language. These results were unrelated to whether the native language was Spanish or English. Hence, emotional specificity for native-language recall was not peculiar to experience in a particular subculture or to the characteristics of a particular language. What our bilingual subjects had in common was that they had all acquired their second language after early childhood. From a structural perspective, such late acquisition of a second language may lead to a co-ordinate or separate representational system that differs substantially from the representational systems of other types of bilinguals (see Javier \& Marcos, 1989). Only further research can determine the extent to which our results can be generalised to those who learn the second language at a younger age.

Although the main finding-language specificity of the emotional advantage in recall- did not reliably depend on how the words were rated, the means show interesting trends. The emotionality of nativelanguage words appeared to be associated with recall when words were rated for pronunciation and emotion but not when rated for activity. In the latter regard, we tentatively propose that the semantic task of rating activity provided a means for retrieval that overrode emotional distinctions.

Regardless of the words' emotionality, the type of rating affected the recall of native-language words differently than the recall of secondlanguage words. The two semantic rating tasks produced better recall than did the nonsemantic task only when words had been presented in the native language. The absence of a levels-of-processing effect for second-language words suggests that subjects paid closer attention on the 
pronunciation task than one would expect in a nonsemantic orienting condition. Further, there is reason to question the nature of processing in that condition on the basis of the rating data; second-language words were judged easier to pronounce than native words. Therefore, results for recall following such ratings should probably be interpreted cautiously.

In conclusion, our results are generally consistent with other research on bilingual memory, but offer some new perspectives for this area as well. On the one hand, our results are consistent with the general consensus expressed by Gerard and Scarborough $(1989$, p. 314$)$ that "any adequate model of linguistic memory must postulate language-specific units (or processes) within an integrated semantic memory". On the other hand, our results deviate from the typically reported exceptions to integrated- or common-store models: language specificity for data-driven tasks (e.g. Durgunoglu \& Roediger, 1987; Smith, 1991) and/or for lexical units/ processes (e.g. Gerard \& Scarborough, 1989; Kirsner, Smith, Lockhart, King, \& Jain, 1984). Language of presentation might be largely or completely irrelevant to the processing of meaning in most contexts, but emotional contexts are the exception to the rule. Late bilinguals' secondlearned language is less likely to be associated with emotional experience and thereby fails to provide the bases for differential elaboration and intralist associations that otherwise would lead to a recall advantage for emotional words.

Manuscript received 6 July 1993

Revised manuscript received 31 January 1994

\section{REFERENCES}

Anooshian, L.J. \& Siegel, A.W. (1985). From cognitive to procedural mapping. In C.J. Brainerd \& M. Pressley (Eds.), Basic processes in memory development: Progress in cognitive development research (pp. 47-101). New York: Springer.

Bloom, L., \& Beckwith, R. (1989). Talking with feeling: Integrating affective and linguistic expression in early language development. Cognition and Emotion, 3, 313-342.

Bloom, L., \& Capatides, J.B. (1987). Expression of affect and the emergence of language. Child Development, 58, 1513-1522.

Boggiano, A.K., \& Hertel, P.T. (1983). Bonuses and bribes: Mood effects in memory. Social Cognition, 2, 49-61.

Bond, M.H. \& Lai, T. (1986). Embarrassment and code-switching into a second language. Journal of Social Psychology, 126, 179-186.

Brown, W.P., \& Ure, D.M.J. (1969). Five rated characteristics of 650 word association stimuli. British Journal of Psychology, 60, 233-249.

Buxbaum, E. (1949). The role of a second language in the formation of ego and superego. International Journal of Psychiatry, 18, 279-482.

Durgunoglu, A.Y., \& Roediger, H.L. (1987). Test differences in accessing bilingual memory. Journal of Memory and Language, 26, 377-391.

Dutta, S. (1975). Affect and memory: A reformulation. Oxford: Pergamon Press. 
Ervin, S. (1964). Language and TAT content in bilinguals. Journal of Abnormal and Social Psychology, 68, 500-507.

Escalona, S.K. (1981). The reciprocal role of social and emotional development advances and cognitive development during the second and third years of life. In E.K. Shapiro \& E. Weber (Eds.), Cognitive and affective growth: Developmentalal interaction (pp. 8795). Hillsdale, NJ: Lawrence Erlbaum Associates Inc.

Fishman, J.A., \& Cooper, R.L. (1969). Alternative measures of bilingualism. Journal of Verbal Learning and Verbal Behavior, 8, 276-282.

Gerard, L.D., \& Scarborough, D.L. (1989). Language-specific lexical access of homographs by bilinguals. Journal of Experimental Psychology: Learning, Memory, and Cognition, $15,305-315$.

Glucksberg, S. (1984). Commentary: The functional equivalence of common and multiple codes. Journal of Verbal Learning and Verbal Behavior, 23, 100-104.

Gonzalez-Reigosa, F. (1976). The anxiety arousing effect of taboo words in bilinguals. In C.D. Spielberger \& R. Diaz-Guerrero (Eds.), Cross-cultural anxiety (pp. 89-105). Washington, DC: Hemisphere.

Greenson, R. (1950). The mother tongue and the mother. International Journal of Psychiatry, $31,18-23$.

Grosjean, F. (1982). Life with two languages: An introduction to bilingualism. Cambridge, MA: Harvard University Press.

Gumperz, J.J. \& Hernandez, E. (1971). Bilingualism, bidialectalism, and classroom interaction in language in social groups. Palo Alto: Stanford University Press.

Javier, R. (1989). Linguistic considerations in the treatment of bilinguals. Journal of Psychoanalytic Psychology, 6, 87-96.

Javier, R.A., \& Marcos, L.R. (1989). The role of stress on the language-independence and code-switching phenomena. Journal of Psycholinguistic Research, 18, 449-472.

Kirsner, K., Smith, M.C., Lockhart, R.S., King, M.L., \& Jain, M. (1984). The bilingual lexicon: Language-specific units in an integrated network. Journal of Verbal Learning and Verbal Behavior, 23, 519-539.

Kolers, P.A. (1963). Interlingual word associations. Journal of Verbal Learning and Verbal Behavior, 2, 291-300.

Kolers, P.A. (1968). Bilingualism and information processing. Scientific American, 218, 78-86

Kolers, P.A., \& Brison, S.J. (1984). Commentary: On pictures, words, and their mental representation. Journal of Verbal Learning and Verbal Behavior, 23, 105-113.

Kolers, P.A., \& Roediger, H.L. (1984). Procedures of mind. Journal of Verbal Learning and Verbal Behavior, 23, 425-449.

MacNamara, J. (1967). The bilingual's linguistic performance: A psychological overview. Journal of Social lssues, 23, 58-77.

Marsh, L.G., \& Maki, R.H. (1976). Efficiency of arithmetic operations in bilinguals as a function of language. Memory \& Cognition, 4, 459-464.

McCormack, P.D. (1977). Bilingual linguistic memory: The independence-interdependence issue revisited. In P.A. Hornby (Ed.), Bilingualism: Social and educational implications (pp. 57-66). New York: Academic Press.

Monti-Belkaoui, J., \& Belkaoui, A. (1983). Bilingualism and the perception of professional concepts. Journal of Psycholinguistic Research, 12, 111-127.

Neisser, U. (1963). The imitation of man by machine. Science, 139, 193-197.

Osgood, C.E. (1952). The nature and measurement of meaning. Psychological Bulletin, 49, 197-237.

Potter, M.C., So, K.F., Von Eckardt, B., \& Feldman, L.B. (1984). Lexical and conceptual representation in beginning and proficient bilinguals. Journal of Verbal Learning and Verbal Behavior, 23, 23-38. 


\section{4}

ANOOSHIAN AND HERTEL

Rubin, D.C., \& Friendly, M. (1986). Predicting which words get recalled: Measures of free recall, availability, goodness, emotionality, and pronunciability for 925 nouns. Memory \& Cognition, 14, 79-94.

Russell, H.J. (1947). The most common Spanish words and idioms. Oxford University Press.

Scarborough, D.L., Gerard, L., \& Cortese, C. (1984). Independence of lexical access in bilingual word recognition. Journal of Verbal Learning and Verbal Behavior. 23, 84-99.

Schwanenflugel, P.J., \& Rey, M. (1986). Interlingual semantic facilitation: Evidence for a common representational system in the bilingual lexicon. Journal of Memory and Language, 25, 605-618.

Smith, M.C. (1991). On the recruitment of semantic information for word fragment completion: Evidence from bilingual priming. Journal of Experimental Psychology: Learning, Memory, and Cognition, 17, 234-244.

Snodgrass, J.G. (1984). Concepts and their surface representations. Journal of Verbal Learning and Verbal Behavior, 23, 3-22.

Thorndike, E.L., \& Lorge, I. (1944). The teacher's word book of 30,000 words. New York: Teachers College, Bureau of Publication.

Watkins, M.J., \& Peynircioglu, Z.F. (1983). On the nature of word recall: Evidence for linguistic specificity. Journal of Verbal Learning and Verbal Behavior, 22, 385-394.

\section{APPENDIX}

\section{Emotional and Neutral Words Selected for the Experiment (Spanish Translations appear in Parentheses)}

\begin{tabular}{ll}
\hline Emotional Words & Neutral Words \\
\hline bed (cama) & wagon (coche) \\
breast (pecho) & window (ventana) \\
death (muerte) & column (columna) \\
father (padre) & box (caja) \\
fight (lucha) & branch (rama) \\
danger (peligro) & bread (pan) \\
warmth (calor) & chair (silla) \\
anger (ira) & tree (árbol) \\
war (guerra) & cow (vaca) \\
laugh (risa) & door (puerta) \\
musis (música) & finger (dedo) \\
friend (amigo) & foot (pie) \\
home (casa) & fur (piel) \\
kiss (beso) & part (parte) \\
mother (madre) & salt (sal) \\
bride (novia) & seat (asiento) \\
party (fiesta) & street (calle) \\
girl (niña) & table (mesa) \\
\hline
\end{tabular}

